\title{
ATUAÇÃO DO CENTRO DE LABORATÓRIO REGIONAL - INSTITUTO ADOLFO LUTZ NO CONTROLE DE QUALIDADE DO DIAGNÓSTICO DA LEISHMANIOSE VISCERAL CANINA
}

Lourdes Aparecida Zampieri D’Andrea, Ana Carolina Fonseca de Oliveira, Mariza Menezes Romão

Centro Laboratório Regional do Instituto Adolfo Lutz de Presidente Prudente V, São Paulo. E-mail: zampieri@ial.sp.gov.br.

\section{RESUMO}

A leishmaniose visceral (LV) é um sério problema de saúde pública e tem se expandido em território paulista. Zoonose causada pelo protozoário Leishmania infantum (sinonímia-Leishmania chagasi), transmitida, principalmente, pela picada do Lutzomyia longipalpis. O presente estudo teve por objetivo analisar a atuação do Centro de Laboratório Regional Instituto Adolfo Lutz de Presidente Prudente, no controle de qualidade do diagnóstico da LV canina, no período entre abril/2012 e abril/2017. No período analisado, foram ministradas 26 capacitações a 28 municípios, para utilizarem o TR DPP BioManguinhos como teste de triagem para LV canina; 60 visitas técnicas a 25 municípios e analisadas 1.126 amostras de soro enviadas pelos serviços de zoonoses municipais para controle de qualidade, sendo 752 amostras não reagentes e 374 reagentes no TR DPP BioManguinhos. É de grande importância em Saúde Pública a atuação do laboratório de referência regional no controle de qualidade do diagnóstico da LVC.

Palavras-chave: Leishmaniose visceral canina, Diagnóstico, Controle de qualidade

\section{ACTIVITY OF THE REGIONAL LABORATORY CENTER ADOLFO LUTZ INSTITUTE IN THE QUALITY CONTROL OF THE DIAGNOSIS OF VISCERAL CANINE LEISHMANIASIS}

\begin{abstract}
Visceral leishmaniasis (VL) is a serious public health problem and it has expanded in São Paulo territory. Zoonosis caused by the protozoan Leishmania infantum (synonymy-Leishmania chagasi), transmitted, primarily, by the bite of Lutzomyia longipalpis. The present study aimed to analyze the performance of the Adolfo Lutz Institute Regional Laboratory Center of Presidente Prudente, in the quality control of the diagnosis of canine VL, in the period of April/2012 and April/2017. In the analyzed period, 26 training courses were given to 28 municipalities to use the QT DPP BioManguinhos as a screening test for canine VL; 60 technical visits to 25 municipalities and analyzed 1,126 serum samples sent by the municipal zoonoses services for quality control, of which 752 were non-reagent samples and 374 were reagents in the QT DPP BioManguinhos. It is of great importance in Public Health the performance of the regional reference laboratory in the quality control of the canine $\mathrm{VL}$ diagnosis.
\end{abstract}

Key words: Canine visceral leishmaniasis, Diagnosis, Quality control 


\section{INTRODUÇÃO}

A leishmaniose visceral (LV) ou calazar é uma zoonose parasitaria que acomete seres humanos e animais, causada pelo protozoário Leishmania infantum (sinonímia-Leishmania chagasi) e na ausência de tratamento, resulta em casos fatais ${ }^{1}$. A principal forma de transmissão do parasito ao homem e a outros hospedeiros vertebrados é pela picada de fêmeas de dípteros, conhecidos genericamente por flebotomíneos ${ }^{2}$. Duas espécies de flebotomíneos são incriminadas no ciclo de transmissão de L. infantum: a Lutzomyia longipalpis e L. cruzi, sendo a primeira considerada a principal espécie transmissora ${ }^{3}$.

Amplamente distribuída no mundo, principalmente em regiões tropicais e subtropicais da Ásia, Oriente Médio, África, América Central e América do Sul, a LV, é endêmica em cerca de 72 países, porém em 2015, 90\% dos casos globais foram reportados em sete países: Brasil, Etiópia, Índia, Quênia, Somália, Sudão do Sul e Sudão ${ }^{4}$.

A LV no Brasil até 1980 apresentava eminentemente caráter rural, mas atualmente vem se expandindo para as áreas urbanas e periurbana devido a ações antrópicas, associadas a adaptação do inseto vetor às modificações ambientais ${ }^{5,6}$.

Para o diagnóstico da LV, estão disponíveis diferentes metodologias podendo ser realizado por meio de exames parasitológicos como o parasitológico direto, que pesquisa as formas amastigotas em lâmina de esfregaço; cultura (in vivo e in vitro) para pesquisa das formas promastigotas da Leishmania e exame histopatológico das lesões; testes imunológicos para pesquisa de anticorpos e identificação de espécies de Leishmania, por isoenzimas e métodos moleculares de amplificação do ácido nucleico, como a Reação em Cadeia da Polimerase (Polymerase Chain Reaction - PCR) e PCR quantitativo (Real Time PCR) (MOREIRA et al., 2007; QUEIROZ et al., 2010) ${ }^{7,8}$.

As estratégias do Programa de Controle da Leishmaniose Visceral (PCLV) baseiam-se na detecção e tratamento de casos humanos (caráter eminentemente curativo) e no controle dos reservatórios domésticos e vetores ${ }^{9}$.

No que se refere ao diagnóstico sorológico canino, o Ministério da Saúde (MS) preconiza através de nota técnica, realização de inquéritos sorológicos para o diagnóstico da leishmaniose visceral canina (LVC), a partir da utilização de duas técnicas laboratoriais, o teste de triagem, realizado de preferência pela esfera municipal, utilizando o teste rápido imunocromatografico (TR) DPP $^{\circledR}$ BioManguinhos e como teste confirmatório, realizado nos Laboratórios Centrais (LACENs) ou em centros de controle de zoonoses (CCZ) municipais, é utilizado o ensaio imunoenzimatico ELISA $^{\circledR}$ BioManguinhos ${ }^{10,11}$. Os municípios só passam a receber os testes e realizar a triagem sorológica com TR DPP BioManguinhos, após se estruturarem com uma equipe mínima de zoonoses e com espaço físico e equipado adequadamente; serem cadastrados; capacitados e passar por supervisão técnica realizada pelo Laboratório de Referência Regional para LV.

São desenvolvidas pelo Instituto Adolfo Lutz (IAL) Central e seus Centros de Laboratórios Regionais, inúmeras capacitações, visitas técnicas (supervisão direta) e controle de qualidade de amostras (supervisão indireta) à profissionais de serviços de controle de vetores/zoonoses municipais e Centro de Controle de Zoonoses (CCZs) para a implantação dos serviços de triagem sorológica para LV canina, assegurando a qualidade do diagnóstico deste agravo no Estado de São Paulo.

A supervisão técnica direta é realizada através de visita técnica aos serviços de triagem sorológica para LVC municipais, com o objetivo de avaliar requisitos de infraestrutura, biossegurança, equipamentos, insumos, recursos humanos, práticas técnicas específicas e de documentação. Já a supervisão indireta é realizada através do envio de soro triado pelos serviços municipais (10\% das amostras testadas não ultrapassando 20) aos IALs Regionais para serem retestadas no TR DPP Biomanguinhos. 
Frente ao arsenal diagnóstico utilizado no enfrentamento da LVC, é de grande importância que haja um programa de controle de qualidade. O Laboratório de Referência Nacional realiza o controle de qualidade dos Laboratórios Centrais (LACENs), e esses, fazem o controle de qualidade dos LACENs Regionais, que por sua vez, atua na esfera municipal. O presente estudo teve por objetivo analisar a atuação do Centro de Laboratório Regional Instituto Adolfo Lutz de Presidente Prudente V, LACEN Regional, no controle de qualidade do diagnóstico da LV canina, no período entre abril/2012 e abril/2017.

\section{MATERIAL E MÉTODOS}

Foi realizado um levantamento de dados referentes ao controle de qualidade do TR DPP BioManguinhos, que inclui o número de capacitações ministradas a servidores municipais pertencentes a municipios da Rede Regional de Atenção a Saúde - RRAS 11 de Presidente Prudente, visitas técnicas e retestagens das amostras de soros enviadas pelos municípios para o controle de qualidade obtidos nos registros do Laboratório de Parasitologia do Núcleo de Ciências Biomédicas, do Centro de Laboratório Regional - Instituto Adolfo Lutz de Presidente Prudente $\mathrm{V}$ (CLR IAL PP V), no período entre abril/2012 e abril/2017. Trata-se de um estudo retrospectivo, cadastrado e aprovado pelo CAAE №. 53247716.8.0000.0059, parecer №. 1.934.175.

\section{RESULTADOS}

Na RRAS 11 de Presidente Prudente, área de abrangência de atuação do CLR IAL PP V, no período de abril de 2012 a abril de 2017, a pesquisadora responsável pelo laboratório de parasitologia e da subrede de Leishmaniose, juntamente com a sua equipe técnica, ministraram 26 capacitações, perfazendo um total de 208 horas a 166 funcionários de nível superior e médio, pertencentes a 28 municípios (Tabela 01), para utilizarem o TR DPP BioManguinhos como teste de triagem sorológica.

Tabela 01. Distribuição por ano do quantitativo de capacitações ministradas a servidores municipais pertencentes à região de Presidente Prudente/SP, conforme o número de municípios, recursos humanos e horas, para utilização do TR DPP BioManguinhos como teste de triagem sorológica no diagnóstico da LVC, realizadas pelo CLR IAL PP V. Período entre abril/2012 e abril/2017

\begin{tabular}{lccccccc}
\hline QUANTIDADE & $\mathbf{2 0 1 2}$ & $\mathbf{2 0 1 3}$ & $\mathbf{2 0 1 4}$ & $\mathbf{2 0 1 5}$ & $\mathbf{2 0 1 6}$ & $\mathbf{2 0 1 7}$ & TOTAL \\
\hline CAPACITAÇÕES & 1 & 5 & 6 & 3 & 8 & 3 & 26 \\
MUNÍCIPIOS & 15 & 7 & 12 & 10 & 7 & 12 & 63 \\
RECURSOS HUMANOS & 45 & 20 & 38 & 20 & 18 & 25 & 166 \\
HORAS & 8 & 40 & 48 & 24 & 64 & 24 & 208 \\
\hline
\end{tabular}

Fonte: CLR IAL PP V.

No período de abril de 2014 a abril de 2017 foram realizadas 60 visitas técnicas a 25 municípios com atividades de triagem sorológica para LVC, sendo emitidos 60 relatórios técnicos, na área de abrangência do CLR IAL PPV (Tabela 02).

No mesmo período (abril/2014 a abril/2017), o CLR-IAL-PPV que é o laboratório de referência regional, recebeu um total de 1.126 amostras de soro enviadas pelos serviços de zoonoses municipais ou CCZs para controle de qualidade (supervisão indireta), sendo que desse total, 752 eram de amostras de soro com resultado não reagente e 374 com resultado reagente no TR DDP BioManguinhos para LVC, em seus respectivos municípios de origem. Todas estas amostras (não reagentes e reagentes) foram retestadas no TR DPP BioManguinhos, com número de lote diferente daquele utilizado no município, resultando em uma concordância de $89,3 \%$ entre os resultados (Tabela 03). 
Tabela 02. Distribuição do quantitativo de visitas técnicas, conforme o município da região de Presidente Prudente/SP, realizadas em atendimento ao programa de controle de qualidade do diagnóstico da LVC na rede de Leishmanioses do IAL, na área de abrangência do CLR IAL PP V. Período entre abril/2014 e abril/2017.

\begin{tabular}{|c|c|c|c|c|c|c|c|}
\hline \multirow[b]{2}{*}{ Municípios } & \multirow[b]{2}{*}{ № } & \multicolumn{6}{|c|}{ Anos } \\
\hline & & 2013 & 2014 & 2015 & 2016 & 2017 & $\begin{array}{c}\mathrm{N} . \\
\text { supervisões }\end{array}$ \\
\hline ALFREDO MARCONDES & 1 & 20/mai & 09/dez & & 12/dez & & 3 \\
\hline ALVARES MACHADO & 2 & & 11/abr & 26/mai & $27 /$ dez & & 3 \\
\hline CAIUÁ & 3 & & & $22 / \mathrm{dez}$ & 04/jan & & 2 \\
\hline DRACENA & 4 & 13/dez & & $10 /$ mar & 09/mar & & 3 \\
\hline EMILIANÓPOLIS & 5 & & & 23/abr & 29/dez & & 2 \\
\hline FLORA RICA & 6 & 14/mai & 02/dez & & $12 / \mathrm{dez}$ & & 3 \\
\hline IRAPURU & 7 & $13 /$ mai & 02/dez & & $09 /$ nov & & 3 \\
\hline JUNQUEIRÓPOLIS & 8 & & 01/jul & & & 04/jan & 2 \\
\hline MARABÁ PAULISTA & 9 & & & $26 /$ nov & & & 1 \\
\hline MONTE CASTELO & 10 & & $09 / a b r$ & & $11 /$ mai & 29/mar & 3 \\
\hline NOVA GUATAPORANGA & 11 & & 06/mai & 09/set & $28 /$ set & & 3 \\
\hline OURO VERDE & 12 & & 13/ago & & & 04/jan & 2 \\
\hline PANORAMA & 13 & & 09/abr & & 13/jul & & 2 \\
\hline PAULICÉIA & 14 & & 08/abr & & $27 / a b r$ & & 2 \\
\hline PIQUEROBI & 15 & & $10 / a b r$ & $22 / \mathrm{dez}$ & & & 2 \\
\hline PRESIDENTE EPITÁCIO & 16 & & & & 02/jun & & 1 \\
\hline PRESIDENTE PRUDENTE & 17 & $13 /$ mar & 05/ago & & $07 /$ nov & & 3 \\
\hline PRESIDENTE VENCESLAU & 18 & & $10 / a b r$ & 05/mai & 06/dez & & 3 \\
\hline RANCHARIA & 19 & & & & $03 /$ nov & & 1 \\
\hline SANTA MERCEDES & 20 & & 06/mai & & $13 /$ jul & & 2 \\
\hline SANTO ANASTÁCIO & 21 & & $11 / a b r$ & 28/dez & & & 2 \\
\hline SANTO EXPEDITO & 22 & 08/out & 09/dez & & 29/dez & & 3 \\
\hline S. JOÃO DO PAU D'ALHO & 23 & & 07/mai & & & $25 /$ jan & 2 \\
\hline TEODORO SAMPAIO & 24 & 15/ago & $23 /$ set & 07/mai & 28/jan & & 4 \\
\hline TUPI PAULISTA & 25 & & $18 /$ fev & $02 /$ jun & 08/ago & & 3 \\
\hline TOTAL & 25 & 7 & 19 & 11 & 19 & 4 & 60 \\
\hline
\end{tabular}

Fonte: CLR IAL PP V. 
Tabela 03. Amostras de soro enviadas pelos serviços de zoonoses municipais ou CCZs para controle de qualidade (supervisão indireta). Período entre abril/2014 e abril/2017

\begin{tabular}{|c|c|c|c|c|c|c|}
\hline \multirow[t]{2}{*}{ MUNICIPIOS } & & \multirow[t]{2}{*}{ № DE AMOSTRAS } & \multicolumn{2}{|c|}{ MUNICIPIO } & \multicolumn{2}{|c|}{$\begin{array}{l}\text { CLR IAL } \\
\text { PPV }\end{array}$} \\
\hline & & & NR & $\mathbf{R}$ & NR & $\mathbf{R}$ \\
\hline ALFREDO MARCONDES & 1 & 4 & 4 & 0 & 3 & 1 \\
\hline ÁLVARES MACHADO & 2 & 22 & 8 & 14 & 8 & 14 \\
\hline CAIUA & 3 & 16 & 11 & 5 & 11 & 5 \\
\hline DRACENA & 4 & 112 & 88 & 24 & 72 & 40 \\
\hline EMILIANÓPOLIS & 5 & 21 & 18 & 3 & 18 & 3 \\
\hline FLORA RICA & 6 & 31 & 27 & 4 & 28 & 3 \\
\hline IRAPURU & 7 & 106 & 78 & 28 & 80 & 26 \\
\hline JUNQUEIROPOLIS & 8 & 76 & 67 & 9 & 62 & 14 \\
\hline MARABÁ PAULISTA & 9 & 1 & 0 & 1 & 0 & 1 \\
\hline MONTE CASTELO & 10 & 36 & 22 & 14 & 22 & 14 \\
\hline NOVA GUATAPORANGA & 11 & 22 & 20 & 2 & 20 & 2 \\
\hline OURO VERDE & 12 & 93 & 78 & 15 & 70 & 23 \\
\hline PANORAMA & 13 & 33 & 21 & 12 & 22 & 11 \\
\hline PAULICEIA & 14 & 16 & 3 & 13 & 3 & 13 \\
\hline PIQUEROBI & 15 & 15 & 12 & 3 & 13 & 2 \\
\hline PRESIDENTE EPITÁCIO & 16 & 5 & 0 & 5 & 0 & 5 \\
\hline PRESIDENTE PRUDENTE & 17 & 127 & 33 & 94 & 49 & 78 \\
\hline PRESIDENTE VENCESLAU & 18 & 131 & 109 & 22 & 101 & 30 \\
\hline RANCHARIA & 19 & 4 & 2 & 2 & 3 & 1 \\
\hline REGENTE FEIJÓ & 20 & 2 & 0 & 2 & 0 & 2 \\
\hline SANTA MERCEDES & 20 & 30 & 18 & 12 & 19 & 11 \\
\hline SANTO ANASTACIO & 21 & 10 & 8 & 2 & 5 & 5 \\
\hline SANTO EXPEDITO & 22 & 37 & 31 & 6 & 32 & 5 \\
\hline SÃO JOÃO DO PAU D'ALHO & 23 & 8 & 6 & 2 & 6 & 2 \\
\hline TEODORO SAMPAIO & 24 & 141 & 72 & 69 & 97 & 44 \\
\hline TUPI PAULISTA & 25 & 27 & 16 & 11 & 15 & 12 \\
\hline TOTAL & 25 & 1126 & 752 & 374 & 759 & 367 \\
\hline
\end{tabular}

NR- Não Reagente / R- Reagente

Fonte: CLR IAL PP V.

\section{DISCUSSÃO}

Desde 2012, a triagem sorológica para o diagnóstico da LV canina, passou a ser de responsabilidade dos municípios, utilizando-se o TR DPP para LV canina e o ELISA, ambos da BioManguinhos, como teste confirmatório, devendo esse, ser realizado pelos LACENs ou em laboratórios dos Centros de Controle de Zoonoses.

Diante disso, passou-se a realizar assessoria e controle de qualidade do diagnóstico através de supervisões técnica direta e indireta aos laboratórios locais. Uma vez o município inserido na rede de Leishmaniose do Estado de São Paulo, passa a receber os kits de TR DPP BioManguinhos fornecidos pelo Ministério da Saúde (MS) e distribuídos pelo IAL, conforme a programação de inquérito sorológico realizada pelo município, da disponibilidade dos insumos e da prestação de 
contas dos testes realizados através de relatórios mensais online. O não cumprimento do acima estipulado levará ao corte do recebimento de insumos.

No período de estudo, foi realizado um elevado número de capacitações pelo CLR IAL PP V para fins de descentralização do diagnóstico da LVC na esfera municipal, demonstrando que está ocorrendo uma dispersão da LV na região de Presidente Prudente, com número crescente de novos municípios, o que demanda uma força tarefa do Laboratório de Referencia Regional.

As visitas técnicas (supervisão direta) é um instrumento importante de avaliação e controle, pois ao término desta atividade é elaborado um relatório técnico, que após ser assinado por todos os presentes durante a visita, o mesmo é oficializado e enviado para cada setor de vigilância em saúde envolvido no PVCLV. Também é muito útil para gestão municipal, por apontar possíveis necessidades de melhoria e intervenção na esfera local.

Pelo grande número de amostras recebidas para controle de qualidade do TR DPP BioManguinhos na supervisão indireta (Tabela 03), percebe-se o compromisso dos serviços de zoonoses municipais, na manutenção da qualidade do diagnóstico realizado. Entretanto, observase pelo índice de concordância (89,3\%) entre os resultados, que é necessário recapacitação de algumas equipes de zoonoses, naqueles municípios onde houve maior discordância entre os resultados.

É de grande importância em Saúde Pública a atuação da Rede de Leishmanioses no controle de qualidade do diagnóstico, apoiando as atividades desenvolvidas na escala municipal, visando efetividade nas ações de vigilância em saúde desse agravo.

\section{REFERÊNCIAS}

1. Dantas FT. Situação atual da epidemiologia da leishmaniose visceral em Pernambuco. Revista de Saúde Pública, São Paulo, v.40, n.3, p.537-541, 2006, https://doi.org/10.1590/S003489102006000300024.

2. Sousa ZFD. Diagnóstico da Leishmaniose visceral em áreas rurais, endêmicas e não endêmicas, utilizando um teste imunocromatográfico recombinante K39, no período de 2004 a 2006. 2007. 142 f. Dissertação (Mestrado em Medicina Tropical) - Universidade Federal de Goiás, Goiânia, 2007.

3. Freire ML. Avaliação de desempenho e custos diretos de kits comercialmente disponíveis no Brasil e do protótipo DAT-LPC para o diagnóstico da leishmaniose visceral humana. 2017. (Dissertação de Mestrado) - Programa de Pós -Graduação em Ciências da Saúde do Centro de Pesquisas René Rachou, Fundação Oswaldo Cruz, Belo Horizonte.

4. World Health Organization. Leishmaniasis (2016 Jan). Disponível em: <http://www.who.int/gho/neglected_diseases/leishmaniasis/en// > acesso em: 25 de julho de 2017.

5. Sousa, TC, Francisco AKPR, Santos BS. Leishmaniose Canina em Brasília, DF: Uma Revisão da Literatura. Tempus actas de saúde colet. Brasília, 9(3), 187-202, set, 2015.

6. Marzochi MAC, Marzochi KBF. Tegumentary and visceral leishmaniases in Brazil. Emerging anthropozoonosis and possibilities for their control. Cad. Saúde Pública 1994; 10:359- 375. 2017.

7. Moreira MA, Luvizotto MC, Garcia JF, Corbett CE, Laurenti MD. Comparison of parasitological, immunological and molecular methods for the diagnosis of Leishmaniasis in dogs with different clinical signs. Vet. Parasitol., v. 145, n. 3-4, p. 245-252, 2007, https://doi.org/10.1016/j.vetpar.2006.12.012. 
8. Queiroz NMGP, Assis J, Oliveira TMFS, Machado RZ, Nunes CM, Buzetti WAS. Diagnóstico da leishmaniose visceral canina pelas técnicas de imunohistoquímica e PCR em tecidos cutâneos em associação com a RIFI e ELISA-teste. Rev. Bras. Parasitol. Vet., v. 19, n. 1, p. 34-40, 2010, https://doi.org/10.4322/rbpv.01901006.

9. Costa $\mathrm{CH}$, Vieira JBF. Mudanças no controle da leishmaniose visceral no Brasil. Rev Soc Bras Med Trop. 2001;34(2):223-8, https://doi.org/10.1590/S0037-86822001000200013.

10. Rangel O, Hiramoto RM, Henriques LF, Taniguchi HH, Ciaravolo RMC, Tolezano JE et al. Classificação epidemiológica dos municípios segundo o Programa de Vigilância e Controle da Leishmaniose Visceral Americana no estado de São Paulo, para 2013. BEPA, Bol. Epidemiol. Paul., v. 10, n. 111, p. 3-14, 2013.

11. D'Andrea LAZ, Samizava EY, Romão MM, Hiramoto RH, Tolezano JE. Leishmaniose Visceral: implantação do teste rápido DPP ${ }^{\circledR}$ BioManguinhos nos inquéritos sorológicos canino na área de abrangência do Instituto Adolfo Lutz de Presidente Prudente/SP. In: DIAS, L.S.; GUIMARÃES, R.B. (Orgs.). Desafios da Saúde Ambiental 1. Tupã: ANAP, 2015b. p. 126-140. Disponível em: <http://www.amigosdanatureza.org.br/biblioteca/livros/categoria/cod/45 > Acesso em: 25 jul. 2017 